\title{
Rapid and Precise Clumped Isotope Composition Analysis by Tunable Infrared Laser Differential Absorption Spectroscopy
}

\author{
ZHENNAN WANG ${ }^{1}$, DAVID D. NELSON ${ }^{2}$, DAVID L.
} DETTMAN $^{1 *}$, J. BARRY MCMANUS $^{2}$, JAY QUADE $^{1}$, KATHARINE W. HUNTINGTON ${ }^{3}$, ANDREW J. SCHAUER ${ }^{3}$, SABURO SAKAI ${ }^{4}$, AND NITZAN YANAY ${ }^{1}$

${ }^{1}$ Department of Geosciences, University of Arizona, Tucson, AZ 85721, USA (dettman@arizona.edu)

${ }^{2}$ Aerodyne Research, Inc., Billerica, MS 01821, USA

${ }^{3}$ Department of Earth and Space Sciences, University of Washington, Seattle, WA 98195, USA

${ }^{4} J a p a n$ Agency for Marine-Earth Science and Technology, Yokosuka, Kaganaga 237-0061, Japan

Carbonate clumped isotope thermometry is one of the most developed applications of the geochemistry of multiply substituted isotopologues. The degree of heavy isotope clumping (e.g., ${ }^{16} \mathrm{O}^{13} \mathrm{C}^{18} \mathrm{O}$ ) provides an independent temperature estimate. We have developed an isotope ratio laser spectrometry method using tunable infrared laser differential absorption spectroscopy (TILDAS) and describe our latest results of gaseous $\mathrm{CO}_{2}$ samples and $\mathrm{CO}_{2}$ derived from carbonate minerals. The TILDAS instrument directly and simultaneously measure four isotopologues involved in the ${ }^{12} \mathrm{C}^{16} \mathrm{O}_{2}+{ }^{13} \mathrm{C}^{16} \mathrm{O}^{18} \mathrm{O} \leftrightarrow{ }^{13} \mathrm{C}^{16} \mathrm{O}_{2}+{ }^{12} \mathrm{C}^{16} \mathrm{O}^{18} \mathrm{O}$ exchange reaction, it does not need isobaric correction as in isotope ratio mass spectrometry (IRMS). The clumped isotopologue precision of $0.01 \%$ ( 1 S.E.) is achieved within 20 minutes using approximately $15 \mu \mathrm{mol}$ of $\mathrm{CO}_{2}$, or $1.5 \mathrm{mg}$ of calcite equivalent. TILDAS reported $\Delta_{16013 \mathrm{C} 180}$ values show a linear relationship with theoretical values, with a very weak dependence on bulk isotope composition. This method can be broadened to other areas of carbonate isotope geochemistry, such as rapid and high precision $(0.01 \%$ ) measurement of conventional stable isotope ratios and $\delta^{17} \mathrm{O}$ in $\mathrm{CO}_{2}$ gas samples.

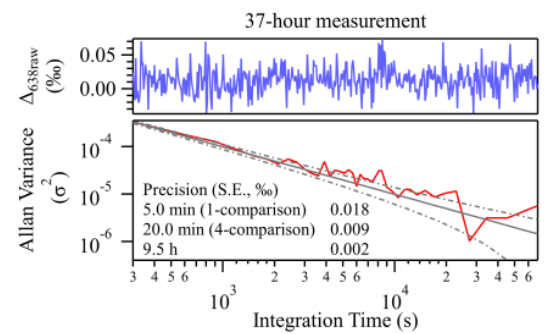

Fig. 1. sample-working reference comparison measurement. 